\title{
RAGAM BAHASA DAN STRATEGI TINDAK TUTUR PEDAGANG ASONGAN DI TERMINAL PURABAYA KOTA SURABAYA
}

\author{
Ziaulhaq \\ SMP Among Siswa Surabaya \\ ulhaqabq20@gmail.com
}

\begin{abstract}
ABSTRAK
Kota Surabaya termasuk salah satu daerah di Provinsi Jawa Timur yang mempunyai terminal yang besar, yaitu Terminal Purabaya. Di terminal tersebut, pedagang asongan menawarkan barang dagangannya dengan menggunakan ragam bahasa dan strategi tindak tutur yang tidak sama antara yang satu dengan yang lain. Fokus penelitian ini adalah (1) ragam bahasa pedagang asongan di Terminal Purabaya saat menawarkan barang dagangannya, (2) strategi tindak tutur pedagang asongan di Terminal Purabaya saat menawarkan barang dagangannya, dan (3) faktor yang memengaruhi adanya ragam bahasa pedagang asongan di Terminal Purabaya saat menawarkan barang dagangannya. Tujuan penelitian adalah memperoleh deskripsi tentang (1) ragam bahasa pedagang asongan di Terminal Purabaya Kota Surabaya saat menawarkan barang dagangannya, (2) strategi tindak tutur pedagang asongan di Terminal Purabaya Kota Surabaya saat menawarkan barang dagangannya, (3) faktor yang mempengaruhi adanya ragam bahasa pedagang asongan di Terminal Purabaya saat menawarkan barang dagangannya. Adapun jenis penelitian yang digunakan adalah penelitian kualitatif yaitu penelitian yang menghasilkan data deskriptif berupa kata-kata tertulis atau lisan dari orang-orang dan perilaku yang diamati. Teknik yang digunakan untuk mengumpulkan data, yakni teknik rekam, teknik simak, teknik wawancara, dan teknik catat. Bersadarkan hasil penelitian, disimpulkan bahwa (1) ragam bahasa pedagang asongan di Terminal Purabaya Kota Surabaya saat menawarkan barang dagangannya dapat dikenali terbatas pada struktur unsur fonologi dan unsur morfologi, (2) strategi tindak tutur meliputi strategi penghormatan dalam menyapa dan strategi perayuan, (3) faktor-faktor yang memengaruhi ragam bahasa adalah faktor waktu, faktor kebiasaan, faktor menarik perhatian pembeli, dan faktor cepat terjual.
\end{abstract}

Kata kunci: pedagang asongan;ragam bahasa; tindak tutur.

ABSTRACT

Surabaya is one of the areas in East Java province which has a large terminal, which is Terminal Purabaya. When the hawkers offering his wares using a variety of language and speech acts strategies are not the same between one another. The focus of this research is the diversity of languages 1. hawkers Terminal Purabaya when offering his wares 2. speech acts strategies of hawkers in Terminal Purabaya when offering his wares 3. Factors that affect their various languages in Terminal Purabaya when offering his wares. Approach researchers to be achieved in this research is to obtain a description of: 1. language diversity of hawkers in Purabaya Terminal Surabaya when offering his wares; 2. 
Strategies speech acts hawkers Purabaya Terminal Surabaya when offering his wares; 3. Factors affecting their various languages hawkers Terminal Purabaya when offering his wares. The type of research used is a qualitative research design research that produces descriptive data in the form of words written or spoken of people and observed behavior. Techniques used include: 1. Mechanical record, 2. Mechanical refer, 3. Interview techniques, and 4. Technical note. The results of the study can conclude (1) Variety language hawkers Purabaya Terminal Surabaya when offering his wares can be recognized limited to the structural elements of the phonological and morphological elements; (2) The strategy of speech acts include: strategy homage in greeting and coaxing strategy; (3) Factors that affect a variety of language is the time factor, habit factors, factors to attract customers, and quickly sold factors.

words: hawkers; speech acts, variety of language.

PENDAHULUAN
Pada hakikatnya, manusia sebagai mahluk sosial sangat membutuhkan bahasa sebagai alat berkomunikasi. Bahasa sebagai alat komuikasi mempunyai peranan yang sangat penting dalam interaksi manusia. Bahasa dapat digunakan manusia untuk menyampaikan pesan, gagasan, keinginan, perasaan, dan pengalamannya kepada orang lain. Dalam kamus linguistik, bahasa adalah sistem lambang bunyi yang dipergunakan oleh para anggota suatu masyarakat untuk bekerja sama, berintraksi, dan mengidentifikasi diri (Kridalaksana, 2011:24).

Kentjono (1982:2) mengatakan bahwa bahasa adalah sistem lambang bunyi arbitrer yang dipergunakan oleh para anggota kelompok sosial untuk bekerja sama, berkomunikasi, dan mengidentifikasikan diri. Sebagai sebuah sistem, bahasa terbentuk oleh suatu aturan, kaidah atau pola-pola tertentu.

Dalam kehidupan bermasyarakat, manusia tidak bisa lepas dari penggunaan bahasa sebagai sarana komunikasi. Samsuri (1980:4) berpendapat bahwa bahasa tidak dapat dipisahkan dari manusia dan mengikuti di dalam setiap pekerjaannya. Dengan demikian, dapat diartikan bahwa bahasa sangat diperlukan, selain fungsinya sebagai alat komunikasi juga sebagai alat untuk meneruskan kebudayaan. Kebudayaan diartikan secara luas, yaitu sistem keseluruhan dari kebiasaan-kebiasaan dan cara hidup manusia, bergaul dari bekerja dalam suatu kelompok (Nababan, 1993:8).

Bahasa digunakan sebagai alat komunikasi kehidupan manusia dan tidak lepas dari kebudyaan masyarakat. Nababan (1984:49) menyatakan bahwa kebudayaan adalah sistem aturan-aturan komunikasi dan interaksi yang memungkinkan suatu masyarakat terjadi, dipelihara, dan dilestarikan.

Perolehan dan penguasaan bahasa secara turun temurun pada pedagang asongan menimbulkan ragam bahasa yang dapat dilihat ketika pedagang asongan menawarkan barang dagangannya. Hal ini dikarenakan pedagang asongan di Kota Surabaya mengalami persentuhan bahasa antara bahasa Jawa dan bahasa Madura yang menunjukkan kekhasan dalam pengucapan. Kekhasan pengucapan kata yang mereka lakukan bertujuan untuk menarik perhatian pembeli sehingga pembeli mempunyai rasa penasaran untuk membeli barang yang mereka tawarkan. 
Penggunaan pengucapan kata yang mereka gunakan tersebut mempunyai variasi bunyi dan variasi kata. Dalam kajian bahasa, ragam bahasa dibahas di bidang sosiolinguistik. Ragam bahasa merupakan salah satu wujud dari variasi bahasa yang mendukung proses komunikasi. Variasi bahasa merupakan cermin tidak seragamnya bahasa dalam masyarakat yang disebabkan oleh lingkungan pemakai bahasa.

Berkaitan dengan ragam bahasa, terdapat penelitian terdahulu yang pernah membahasnya, yaitu, penelitian oleh Septy Silvia Sari (2012) dengan judul Analisis Tindak Tutur Penjual dan Pembeli di Pasar Satwa dan Tanaman Hias Yogyakarta: kajian pragmatik". Tujuan penelitian Sari adalah untuk mendeskripsikan bentuk tindak tutur dan jenis tindak tutur ilokusi yang terdapat dalam komunikasi penjual dan pembeli di Pasar Satwa dan Tanaman Hias Yogyakarta (PASTY). Setting penelitian ini dilakukan di PASTY.

METODE

Tahap pengumpulan data pada penelitian ini menggunakan empat teknik, yaitu (1) teknik rekam, (2) teknik simak, (3) wawancara dan (4) teknik catat. Teknik rekam merupakan cara untuk mencari data berupa kata-kata yang dipakai atau dihasilkan oleh pedagang asongan dengan menggunakan teknik sadap (tersembunyi). Teknik simak dapat disejajarkan dengan metode observasi atau pengamatan (Sudaryanto, 993:4). Teknik simak dalam hal ini dilakukan dengan mendengar percakapan yang secara langsung dari alat perekam untuk memperoleh data tentang ragam bahasa pedagang asongan yang muncul. Teknik wawancara ini digunakan untuk memperoleh informasi data dengan mengadakan tanya jawab. Dalam penelitian, yang digunakan adalah metode wawancara bebas terpimpin. Arikunto (1998:45) menyatakan wawancara bebas terpimpin adalah wawancara yang pewawancaranya hanya membawa garis besar sebagai pedoman tentang hal yang akan ditanyakan. Peneliti terlibat langsung untuk mengadakan tanya jawab dengan pedagang asongan di Terminal Purabaya Kota Surabaya. Teknik pencatatan dalam penelitian ini digunakan untuk mencatat hal-hal yang dianggap perlu dan penting. Selanjutnya dilakukan pencatatan sehingga data yang semula berwujud lisan menjadi data yang berwujud tertulis. Data dikelompokkan berdasar atas tuturan yang mengandung faktor penyebab ragam bahasa pedagang asongan di terminal Purabaya Kota Surabaya.

Sumber data dalam penelitian data ini berupa tuturan yang dipakai atau dihasilkan oleh para pedagang asongan saat menawarkan barang yang mengandung ragam bahasa pedagang asongan di Terminal Purabaya Kota Surabaya.

Analisis data dilakukan secara deskriptif interpretatif. Metode deskriptif interpretatif adalah data-data yang diperoleh diinterpretasikan sesuai dengan data alamiah yang ada. Langkah-langkah yang dilakukan oleh peneliti dalam menganalisis data sebagai berikut.

1). Tahap persiapan

a. data yang terekam ditranskripkan ke dalam bentuk teks

b. pemilihan data

2). Tahap pengelompokan data

a. klasifikasi data menurut ciri ragam bahasa

b. penjelasan data 
Hal yang dibahas dalam pebelitian ini adalah (1) ragam bahasa pedagang asongan, (2) strategi tindak tutur pedagang asongan saat menawarkan barang dagangannya, dan (3) faktor penyebab adanya ragam bahasa pedagang asongan saat menawarkan barang dagangannya. Ragam Bahasa Pedagang Asongan

Rochayah (1995:13) menyatakan bahwa ragam bahasa dapat dikenali antara lain dari ciri-cirinya. Ciri-ciri yang dimaksud adalah pilihan kata seperti leksikal, struktur seperti fonologi, morfologi, dan sintaksis, serta intonasi seperti pada aksennya. Dalam penelitian ini, ciri ragam yang akan dibahas terbatas pada struktur yakni unsur fonologi dan unsur morfologi.

\section{Ciri Ragam Bahasa Pedagang Asongan Berdasarkan Ciri Fonologi}

Pada saat menjajakan dagangannya, pedagang asongan menunjukan adanya perubahan fonem, penghilangan fonem, dan penambahan fonem.

\section{A. Perubahan Fonem}

Perubahan fonem berdasarkan ciri fonologi merupakan berubahnya bunyi atau fonem pada sebuah kata agar kata menjadi terdengar dengan jelas atau untuk tujuan tertentu. Perubahan fonem terlihat dalam segmen tutur berikut.

\section{a. Fonem [i]}

(1) Rotehsepolo tiga, sepolo tiga, murah-murah rotehnya.

Kata "roti" terjadi perubahan fonem bunyi vokal tinggi depan [i] menjadi bunyi vokal sedang depan [e] sehingga kata roti menjadi kata roteh. Proses perubahan fonem pada kata roti menjadi roteh disebut proses netralisasi karena terjadi perubahan fonem akibat pengaruh lingkungan.

\section{b. Fonem [u]}

(2) Yang taho-taho, taho petis poyo-poyo. Taho dek yo. Ayo taho petis, poyo, taho-tahone dek? Onok petise Mas, ato kacang? Opo nak, poyo nak yo?

Bunyi vokal tinggi belakang $[\mathrm{u}]$ pada segmen tutur (2) pada kata "tahu” sering diucapkan [o] sehingga menjadi "taho". Perubahan fonem vokal [u] menjadi fonem vokal [o] pada kata "taho" disebut proses netralisasi karena terjadi perubahan fonem akibat pengaruh lingkungan pedagang asongan di terminal Purabaya Kota Surabaya.

(3) Ndog poyo-ndog poyo. Taho petis-taho petis. Yang taho-taho. Ndog poyo. Taho petis non. Tahone taho petis buat cemilan.

Kata "puyuh" pada segmen tutur (3) yang diucapkan "poyo" terjadi perubahan fonem vokal tinggi belakang $[\mathrm{u}]$ menjadi fonem vokal sedang belakang [o] pada kata tersebut sehingga dilafalkan "poyo". 
Bunyi vokal tinggi pada kata "tahu” sering diucapkan [o] sehingga menjadi "taho".

(4) Rotehsepolo tiga, sepoloh tiga, murah-murah rotehnya.

Kata sepuluh yang diucapkan sepolo pada segmen tutur (4) terjadi perubahan fonem vokal tinggi belakang $[\mathrm{u}]$ menjadi fonem vokal sedang belakang [o] pada kata tersebut sehingga dilafalkan sepolo.

(5) Yang taho-taho, taho petis poyo-poyo. Taho dek yo. Ayo taho petis, poyo, taho-tahone dek? Onok petise Mas, ato kacang? Opo nak, poyo nak yo?

(6) Jerok-jerok. Jero'e legi jerok'e. sek bungkus empat ribu, manis jeroknya, eh jeroknya dak beli sayang?

(7) Ndog poyo-ndog poyo. Taho petis-taho petis. Yang taho-taho. Ndong poyo. Taho petis non. Tahone taho petis buat cemilan.

Kata tahu yang diucapkan taho pada segmen tutur (5), kata jeruk yang diucapkan jerok pada tindak tutur (6) dan kata puyuh yang diucapkan poyo pada tindak tutur (7) terjadi perubahan fonem vokal tinggi belakang $[\mathrm{u}]$ menjadi fonem vokal sedang belakang [o] pada kata tersebut sehingga dilafalkan taho, poyo dan jerok. Proses perubahan fonem [u] pada kata tahu, poyo dan jerok disebut proses netralisasi karena terjadi perubahan fonem $[\mathrm{u}]$ akibat pengaruh lingkungan. Pedagang asongan di Terminal Purabaya Kota Surabaya tergolong dwi bahasawan sehingga saat pedagang asongan menjajakan barangdagangannya, kata-kata yang akan diucapkan tanpa suatu perencanaan.

\section{B. Penghilangan Fonem}

Penghilangan fonem berdasarkan ciri fonologi merupakan hilangnya bunyi atau fonem pada awal, tengah dan akhir sebuah kata tanpa mengubah makna. Penghilangan ini biasanya berupa pemendekan kata. Penghilangan fonem terlihatdalam segmen tutur berikut.

\section{a. Fonem [e]}

(8) Ndog poyo-ndog poyo. Taho petis-taho petis. Yang taho-taho. Ndong poyo. Taho petis non. Tahone taho petis buat cemilan.

Kata $n d o g$ pada segmen tutur (8) terjadi penghilangan fonem vokal sedang depan [e], sehingga kata endog dilafalkan ndog. Proses penghilangan fonem vokal [e] pada kata endog menjadi ndog disebut proses aferesis karena pada kata endog terjadi proses penghilangan atau penanggalan satu atau lebih fonem pada awal kata.

\section{b. Fonem [h]}

(9) Ndog poyo-ndog poyo. Taho petis-taho petis. Yang taho-taho. Ndog poyo. Taho petis non. Tahone taho petis buat cemilan. 
Kata puyuh pada segmen tutur (9) terjadi penghilangan fonem konsonan bersuara frikatif glotal [h] sehingga kata puyuh dilafalkan poyo. Proses penghilangan fonem konsonan bersuara $[\mathrm{h}]$ disebut proses apokop karena pada kata puyuh terjadi penghilangan atau penanggalan satu atau lebih fonem pada akhir kata. Kata puyuh yang diucapkan poyo terjadi perubahan fonem vokal tinggi belakang [u] menjadi fonem vokal sedang belakang [o] pada kata tersebut sehingga dilafalkan poyo. Penghilangan fonem [h] pada pada kata puyuh menjadi poyo disebabkan oleh pedagang asongan di Terminal Purabaya Kota Surabaya yang terdiri dari masyarakat Madura dan Jawa. Perubahan fonem konsonan [u] pada kata puyuh menjadi fonem [o] yang dilafalkan menjadi poyo, serta penghilangan fonem $[\mathrm{h}]$ sehingga menjadi kata poyo. Pengucapan kata poyo merupakan ciri khas orang Madura yang terbiasa mengucapkan fonem $[\mathrm{u}]$ menjadi fonem [o].

(10) Roteh sepolo tiga, sepolo tiga, murah-murah rotehnya.

Kata sepuluh pada segmen tutur (11) dan (12) terjadi penghilangan fonem konsonan bersuara frikatif glotal [h] sehingga kata sepuluh dilafalkan sepolo. Proses penghilangan fonem konsonan bersuara [h] disebut proses apokop karena pada kata sepuluh terjadi penghilangan atau penanggalan satu atau lebih fonem pada akhir kata. Kata sepuluh yang diucapkan sepolo terjadi perubahan fonem vokal tinggi belakang [u] menjadi fonem vokal sedang belakang [o] pada kata tersebut sehingga dilafalkan sepolo. Penghilangan fonem [h] pada pada kata sepuluh menjadi sepolo disebabkan oleh pedagang asongan di Terminal Purabaya Kota Surabaya yang terdiri dari masyarakat Madura dan Jawa.

\section{Penambahan Fonem}

Penambahan fonem pada ciri fonologi pada suatu kata berupa penambahan bunyi vokal maupun konsonan. Penambahan ini dilakukan untuk kelancaran ucapan. Penambahan fonem terlihat dalam segmen tutur berikut.

\section{a. Fonem [w]}

(11) Aquwa, mison, pokari, teh, dingin, yang haus, mison, aqwa, mizon, poari, dingin-dingin.

(12) Pak, Buk, dingin, Pak, Buk. Aquwa dingin, aquwa dingin. Aquwa dingin buk.

(13) Yang minum dingin-dingin, permen tisu kacang. Yang nyemil kacang-kacang. Aquwane, misone dingin-dingin. Persiapan di dalam bis aquwa permin tisu. Permen mison, aquwa, kacang.

(14) Aquwa, mison, pokari, teh pucuk, dingin-dingin yang haushaus. Kacang, mete. Gurih renyah. Baru-baru.

Kata aqua pada segmen tutur (11), (12), (13) (14) dan (19) terjadi penambahanfonem konsonan semivokal bilabial [w] sehingga kata aqua seolah-olah terdengar aquwa. Proses penambahan fonem konsonan [w] pada kata aqua menjadi aquwa disebut proses epentesis karena terjadi 
penambahan atau pembubuhan fonem pada tengah kata, yaitu kata aqua menjadi aquwa.

\section{Ciri Ragam Bahasa Pedagang Asongan Berdasarkan Ciri Morfologi}

Pada saat pedangan asongan menjajakan barang dagangannya, sering terdengar penambahan morfem dan pengulangan morfem.

\section{A. Penambahan Morfem}

Penambahan morfem yang digunakan pedagang asongan di terminal Purabaya Kota Surabaya ditampilkan pada data berikut.

(15) Salak, salak'e legi limang ewu-limang ewu, murah

(16) Jerok-jerok. Jero'e legi jerok'e. sek bungkus empat ribu, manis jeroknya, eh jeroknya dak beli Jerok-jerok. Jerok'elegi jerok'e. sek bungkus empat ribu, manis jeroknya, eh jeroknya dak beli sayang?

(17) Ndog poyo-ndog poyo. Taho petis-taho petis. Yang taho-taho. Ndog poyo. Taho petis non. Tahone taho petis buat cemilan.

(18) Anggur-anggur. Sak bungkus limang ewu anggure. Anggure sak bungkus limang ewu. Sak bungkus limang ewu. Manis-manis. Anggur yo mas!!!. Anggure murah anggure. Buat oleh-oleh mas, bak, manis-manis. Monggo monggo monggo.

(19) Yang minum dingin-dingin, permen tisu kacang. Yang nyemil kacang-kacang. Aquwane, misone dingin-dingin. Persiapan di dalam bis aquwa permin tisu. Permen mison, aquwa, kacang.

(20) Pak, Buk, salak'e, monggo salak'e

(21) Pak, Buk, monggo getuk pisang. Getuk pisang. Mas getuk'e mas, damel oleh-oleh. Taseh anget mas. Monggo getuk'e-getuk'e.

(22) Sabuk-sabuk'e murah-murah, limolasan, model baru. Gayagaya.

(23) Nasi bungkuse Pak. Telor. Ayam. Daging. Nasi-nasi.

(24) Pecine-pecine, yo kopyah-kopyah. Limang ewuan-limang ewuan banyak warnah dipilih-dipilih.

(25) Sayang anak-sayang anak, baca buku-buku bacaan ada. Cerita juga ada, mewarnai juga ada. Dipilih-dipilih, sepuluh tigasepuluh tiga. Ayo bukunya-bukunya.

(26) Lengkenge-lengkenge sepuluh ewu. Loro limolas. Manis-manis.

Berdasarkan hasil transkripsi ragam bahasa pedagang asongan pada data di atas, diketahui bahwa terdapat kecenderungan penambahan akhiran -e, -ne, dan -nya. Berdasarkan data di atas, akhiran -e, -ne, dan -nya merupakan morfem terikat sehingga tidak bisa berdiri sendiri tanpa melekat pada morfem bebas pada kata salak'e, jerok'e, tahone, anggure, aquwane, getuk'e, sabuk'e, bungkuse, pecine ,bukunya, dan lengkenge. Dari segi makna, akhiran -e, -ne, dan -nya menunjukkan milik. Seperti pada kata bukunya yangberarti buku milik dia. Begitu juga akhiran -e dan -ne pada kata bahasa Jawa yang juga berarti milik. Misalnya pada kata salak'e, jerok'e,. Secara fonologis bentuk akhiran -e dan -ne berbeda, namun secara morfologis bermakna sama yaitu menyatakan milik. Tetapi khusus tuturan yang terlihat pada pedagang asongan, baik akhiran -nya 
(dalam bahasa Indonesia) dan akhiran - $e$ dan -ne (dalam bahasa Jawa) tidak menyatakan milik, tetapi hanya sebagai penunjuk, misalnya "anggure" menyatakan "ini anggur".

Penambahan morfem tersebut cenderung dipengaruhi oleh tuturan yang dihasilkan pedagang asongan dalam mengucapkan kata-kata tersebut sehingga pengucapan tersebut dirasakan sudah menjadi kebiasaan.

\section{B. Pengulangan Morfem}

Proses pengulangan morfem atau reduplikasi merupakan pengulangan satuan gramatik, baik seluruhnya maupun sebagian, baik dengan variasi fonem maupun tidak. Data yang menunjukkan pengulangan morfem ditampilkan sebagai berikut.

(27) Salak'e, salak'e legi limang ewu-limang ewu, murah

(28) Yang taho-taho, taho petis poyo-poyo. Taho dek yo. Ayo taho petis, poyo, taho-tahone dek? Onok petise Mas, ato kacang? Opo nak, poyo nak ye?

(29) Jerok-jerok. Jerok'elegi jerok'e. sek bungkus empat ribu, manis jeroknya, eh jeroknya dak beli sayang?

(30) Aquwa, mison, pokari, teh, dingin, yang haus, mison, aqwa, mizon, poari, dingin-dingin.

(31) Pak, Buk, dingin, Pak, Buk. Aquwa dingin, aquwa dingin. Aquwa dingin buk.

(32) Ndog poyo-ndog poyo. Taho petis-taho petis. Yang taho-taho. Ndong poyo. Taho petis non. Tahone taho petis buat cemilan.

(33) Kipas-kipas, kacang dawung. Lenjo-lenjo. Dawung.

(34) Anggur-anggur. Sak bungkus limang ewu anggure. Anggure sak bungkus limang ewu. Sak bungkus limang ewu. Manis-manis. Anggur yo mas!!!. Anggure muranh anggure. Buat oleh-oleh mas, bak, manis-manis. Monggo monggo monggo.

(35) Usus ayam seribu, seribu, seribu. Yang usus, seribu, seribu.

(36) Taho petis-taho petis, taho petis, taho-taho petis, petis, taho petis.

(37) Yang minum dingin-dingin, permen tisu kacang. Yang nyemil kacang-kacang. Aquwane, misone dingin-dingin. Persiapan di dalam bis aquwa permin tisu. Permen mison, aquwa, kacang.

(38) Pak, Buk, salak'e-salak'e, monggo salak'e

(39) Mas salak murah-murah mas. legi niki, sak estu. Nek boten legi sampean wanosulaken. Angsal kirang kok Mas.

(40) Pak, Buk, monggo getuk pisang. Getuk pisang. Mas getuk'e mas, damel oleh-oleh. Taseh anget mas. Monggo getuk'e-getuk'e.

(41) Aquwa, mison, pokari, teh pucuk, dingin-dingin yang haus-haus. Kacang, mete. Gurih renyah. Baru-baru.

(42) Sabuk-sabuk $e$ murah-murah, limolasan, model baru. Gayagaya.

(43) Sayang anak-sayang anak, baca buku-buku bacaan ada. Cerita juga ada, mewarnai juga ada. Dipilih-dipilih, sepuluh tigasepuluh tiga. Ayo bukunya-bukunya.

(44) Nasi bungkuse Pak. Telor. Ayam. Daging. Nasi-nasi.

(45) Pecine-pecine, yo kopyah-kopyah. Limang ewuan-limang ewuan banyak warnah dipilih-dipilih. 
(46) Lengkenge-lengkenge sepuluh ewu. Loro limolas. Manis-manis.

(47) Rotehsepolo tiga, sepolo tiga, murah-murah rotehnya.

Pengulangan morfem yang terjadi pada pedagang asongan, baik pada morfem bebas maupun pada morfem terikat yang melekat pada morfem bebas (morfem terikat - $e$ dan -ne) sudah menjadi hal yang biasa dilakukan oleh para pedagang asongan di Terminal Purabaya Kota Surabaya.

\section{Strategi Tindak Tutur Pedagang Asongan saat Menawarkan Barang Dagangannya}

Menurut Corder (dalam Andianto, 2004:45) strategi tindak tutur merupakan upaya penutur mengaitkan tujuan penuturan dengan alat yang digunakan untuk mengekspresikan. Dari hasil data yang diperoleh dalam penelitian, strategi tindak tutur pedagang asongan saat menawarkan barang dagangannya di terminal Purabaya Kota Surabaya mencakup beberapa hal, yaitu (1) strategi penghormatan dalam menyapa dan (2) strategi perayuan.

\section{Strategi penghormatan dalam menyapa}

Tindak tutur penghormatan dalam menyapa pada pedagang asongan terlihat dalam segmen tutur (48), (49), dan (50) sebagai berikut.

(48) Yang taho-taho, taho petis poyo-poyo. Taho dek yo. Ayo taho petis, poyo, taho-tahone dek? Onok petise sayang, ato kacang? Opo nak, poyo nak yo?

(49) Jerok-jerok. Jero'e legi jerok'e. sek bungkus empat ribu, manis jeroknya, eh jeroknya dak beli ndok?

(50) Ndog poyo-ndog poyo. Taho petis-taho petis. Yang taho-taho. Ndog poyo. Taho petis non. Tahone taho petis buat cemilan.

Ketiga segmen tutur diatas merupakan salah satu bentuk tindak tutur menawarkan dengan penghormatan dalam menyapa.

\section{Strategi perayuan}

Merayu merupakan tindakan yang dilakukan oleh seseorang terhadap orang lain dengan cara yang diupayakan semanis mungkin sehingga merasa senang melakukan sesuatu sesuai dengan kehendak yang diinginkan.

(51) Anggur-anggur. Sak bungkus limang ewu anggure. Anggure sak bungkus limang ewu. Sak bungkus limang ewu. Manis-manis. Anggur yo mas!!!. Anggure murah anggure. Buat oleh-oleh mas, bak, manis-manis. Monggo monggo monggo.

(52) Mas salak murah-murah mas. legi niki, sak estu. Nek boten legi sampean wangsulaken. Angsal kirang kok Mas.

(53) Pak, Buk, monggo getuk pisang. Getuk pisang. Mas getuk'e mas, damel oleh-oleh. Taseh anget mas. Monggo getuk'e-getuk'e.

Pada segmen tutur (51) yang dituturkan dengan nada lugas dan dengan menggunakan salah satu sapaan penghormatan berupa kata "Mbak, Mas" kepada pembeli. Pedagang asongan merayu pembeli untuk membeli barang dagangannya. Pada segmen tutur (52) yang dituturkan 
dengan nada lugas. Pedagang asongan merayu pembeli dengan berusaha meyakinlan pembeli, dengan harapan akan membeli barang dagangannya. Pada segmen tutur (53) yang dituturkan dengan menggunakan nada lugas serta dengan menggunakan kata sapaan penghormatan berupa kata "Pak, Buk, Mas". Pedagang asongan merayu pembeli untuk membeli barang dagangannya.

\section{Faktor yang Menyebabkan Adanya Ragam Bahasa Pedagang Asongan Saat Menawarkan Barang}

Dari hasil pengamatan dan wawancara diperoleh faktor-faktor yang menyebabkan adanya ragam bahasa pedagang asongan. Faktor yang mempengaruhi pedagang asongan meliputi faktor waktu, faktor kebiasaan, faktor perhatian menarik pembeli, dan faktor agar cepat lak

\section{Faktor waktu}

Pedagang asongan saat menawarkan barang dagangannya rata-rata menggunakan kata-kata yang biasa diulang-ulang, serta berintonasi cepat, seperti tampak pada kutipan berikut.

(54) Salak'e, salak'e legi limang ewu-limang ewu, murah

(55) Aquwa, mison, pokari, teh, dingin, yang haus, mison, aquwa, mizon, pokari, dingin-dingin.

(56) Kipas-kipas, kacang dawung. Lenjo-lenjo. Dawung.

(57) Usus ayam seribu, seribu, seribu. Yang usus, seribu, seribu.

Hal ini disebabkan terbatasnya waktu yang ada untuk berjualan di dalam bis, membuat para pedagang asongan membuat intonasi lebih cepat daribiasanya dan kata-katanya diulang-ulang agar mudah diingat. Bis yang berhenti di Terminal hanya 5-10 menit, dan akan datang lagi bis urutan berikutnya.

\section{Faktor kebiasaan}

Penggunaan bahasa oleh pedagang asongan terbiasa dengan intonasi yang cepat. Hal ini disebabkan adanya kebiasaan yang telah turun temurun digunakan untuk menawarkan barang.

(58) Kipas-kipas, kacang dawung. Lenjo-lenjo. Dawung.

(59) Lengkenge-lengkenge sepuluh ewu. Loro limolas. Manis-manis.

Pada segmen (58) dan (59) terdapat pengucapan yang salah "dawung dan lenjo" yang seharusnya "kedawung dan blenjo" hal ini diakibatkan pengucapan yang agak cepat tanpa memerhatikan tulisan yang sebenarnya.

\section{Faktor menarik perhatian pembeli}

Pedagang asongan yang biasa menawarkan barang dagangannya dengan cara memberikan banyak pilihan warna, barang keluaran terbaru, dan menawarkan dengan membeli banyak harga bisa lebih murah, menggunakan kata-kata yang bisa menarik perhatian pembeli dan membuat rasa penasaran pada pembeli. Hal ini tampak pada tuturan berikut.

(60) Sabuk-sabuk e murah-murah, limolasan, model baru, gaya-gaya. 
(61) Sayang anak-sayang anak, baca buku, buku bacaan ada. Cerita juga ada, mewarnai juga ada. Dipilih-dipilih, sepuluh tigasepuluh tiga. Ayo bukunya-bukunya.

(62) Pecine-pecine, yo kopyah-kopyah. Limang ewuan-limang ewuan banyak warnah dipilih-dipilih.

Pada segmen (60) dituturkan "model baru, gaya-gaya" dengan tuturan model baru dan gaya-gaya, akan membuat orang penasaran dengan model baru dan gaya seperti yang dimaksudkan. Pada segmen (61) terdapat tuturan "sepuluh tiga" sudah dapat tiga buku dengan tiga macam bacaan, sering membuat orang yang awalnya enggan membelinya, akhirnya mau membelinya. Begitu juga dengan segmen (62) juga ada tuturan "banyak warnah dipilih-dipilih" akan membuat orang ada ketertarikan untuk melihat-lihat dulu, dan pada akhirnya jika ada yang cocok akan dibeli.

\section{Faktor agar cepat terjual}

Pedagang asongan saat menawarkan barang dagangannya biasa menunjukkan bahasa yang khas.

P1 : "Yang taho-taho, taho petis poyo-poyo. Taho dek yo. Ayo taho petis, poyo, taho-tahone dek? Onok petise Mas, ato kacang? Opo nak, poyo nak yo?"

P2: "Ndog poyo-ndog poyo. Taho petis-taho petis. Yang taho-taho. Ndog poyo. Taho petis non. Tahone taho petis buat cemilan."

P3 : "Taho petis-taho petis, taho petis, taho-taho petis, petis, taho petis"

Pada ketiga penjual tersebut terlihat menjual barang yang sama, yaitu tahu, telur, dan puyuh. Meski demikian, tuturan yang diucapkan tiap orang berbeda-beda. Hal tersebut menunjukkan ciri khas masingmasing.

SIMPULAN

Dalam penelitian ini, ragam bahasa yang digunakan dapat dikenali terbatas pada struktur unsur fonologi dan unsur morfologi. Ciri-ciri fonologi yang sering digunakan pedagang asongan saat menjajakan barang dagangannya ditandai dengan adanya perubahan fonem, penghilangan fonem, dan penambahan fonem. Perubahan fonem terjadi akibat pergeseran suatu fonem pada kata, misalnya kata tahu menjadi (taho), kata roti menjadi (roteh). Hal tersebut menunjukkan bahwa terjadi pergeseran fonem vokal (u) menjadi fonem (o). Fonem vokal (e) pada kata (endog) sering hilang saat diucapkan berulang-ulang menjadi (ndog). Kata aqua sering diucapkan (aquwa) terjadi penambahan fonem (w) sehingga kata aqua menjadi (aquwa). Pada ciri-ciri morfologi, terdapat penambahan morfem dan pengulangan morfem. Penambahan morfem itu berupa penambahan akhiran $e$ atau ne yang melekat pada morfem bebas, misalnya salak'e, jerok'e, tahone, anggure, aquwane, getuk'e, sabuk'e, bungkuse, pecine dan seterusnya. Selain Penambahan morfem terdapat pula pengulangan morfem, misalnya pada kata (salaksalak'e), (taho-tahone), (dingin-dingin) dan seterusnya. 
Strategi tindak tutur yang terjadi pada pedagang asongan di terminal Purabaya Kota Surabaya ditemukan beberapa hal, yaitu strategi penghormatan dalam menyapa dan strategi perayuan.

Faktor-faktor yang mempengaruhi ragam bahasa pedagang asongan di terminal Purabaya Kota Surabaya adalah faktor waktu, faktor kebiasaan, faktor menarik perhatian pembeli, dan faktor cepat terjual.

\section{DAFTAR PUSTAKA}

Arikunto, Suharsimi. 1998. Prosedur Penelitian: Suatu Pendekatan. Jakarta: Rineka Cipta.

Kentjono, Djoko, (Ed). 1982. Dasar-dasar Linguistik Umum. Jakarta: Fakultas Sastra Universitas Indonesia.

Nababan, PWJ. 1984. Sosiolinguistik Suatu Pengantar. Jakarta: PT. Gramedia.

Nababan, PWJ. 1993. Sosiolinguistik: Suatu Pengantar. Jakarta: PT. Gramedia Pustaka Utama.
Rochayah. 1995. Sosiolinguistik. Bandung: Angkasa.

Samsuri. 1980. Analisis Bahasa: Memahami Bahasa Seacara Ilmiah. Jakarta: Penerbit Erlangga.

Sudaryanto. 1993. Metode dan Aneka Teknik Pengumpul Data. Yogyakarta: Gajah Mada University Press. 